\title{
Hierarchical Routing Techniques for Wireless Sensor Networks: A Comprehensive Survey
}

\author{
Ruchi Aggarwal $^{1}$, Anupam Mittal ${ }^{2}$ and Ramandeep Kaur ${ }^{3}$ \\ ${ }^{1,2,3}$ Department of Computer Sci. \& Engg., Chandigarh University, Gharuan \\ ${ }^{1}$ Assistant Professor, ${ }^{2}$ Assistant Professor, ${ }^{3}$ Student \\ ${ }^{1}$ ruchi1705143@gmail.com, ${ }^{2}$ anupam.cgc@gmail.com \\ ${ }^{3}$ rimmiramandeep@gmail.com
}

\begin{abstract}
This paper describes the concept of routing in wireless sensor networks. Routing algorithm provides reliable path from source to destination. Energy efficiency is main constraint in Wireless Sensor Networks. For improving life time and energy consumption various routing algorithms have been proposed. In this paper describe the hierarchical routing techniques. Hierarchical routing includes tree based routing, cluster based routing, chain based protocol, and grid based routing. And also compare the hierarchical routing techniques.
\end{abstract}

Keywords: Wireless Sensor Networks, Clustering, Routing Techniques

\section{Introduction}

Computer networks are mainly classified into two categories wireless networks and wired networks. In today's technology a time of wireless network technology. Wireless network reduces the cost of wired architecture; provide flexibility in transmission of data. Mobile phone network is an example of wireless technology. Wireless sensors are also used in wireless technology. Wireless Sensor Networks (WSNs) has generated interest in both the industry and in the research field. Wireless sensors are used now days in many applications such as environmental monitoring, traffic analysis, remote sensing etc. Wireless sensors have many working units. Main four working units are: transmission rate, power consumption, scheduling of nodes, computation. In wireless sensors mainly these challenges as: limited energy, communication capability, storage and bandwidth are main resource constraints. Wireless sensor network have problem of lifetime of networks because sensors are used in large geographical areas. In wireless sensor networks difficult to exchange batteries or recharge the batteries when nodes are deployed in large areas. Wireless sensor networks are made from several nodes. Sensors are connected by nodes to each other. Sensor nodes have ability to communicate with each other and a base station.

In Wireless sensors for increase the lifetime of networks to use a minimum energy as delay free processing of data. [1] Minimum energy is used by proper grouping of nodes as clusters. Clustering is design methodology to control the network energy consumption. Clusters make a group of nodes as one and decrease the number of nodes for communication. In each cluster one node is selected as a cluster head $(\mathrm{CH})$ on basis of some criteria. Cluster head $(\mathrm{CH})$ receive data from nodes and transfer to base station. Clustering reduce energy consumption. Several protocols have been described in this paper, which increases the network life time by usage of cluster based approach. [2] Clustering algorithms are used on the basis of routing protocols as flat structure, hierarchical structure, multipath routing etc.

In this paper Section II describes the related work, Section III describes clustering routing protocols and Section IV describes hierarchical routing algorithms. Section V 
describe conclusion of paper.

\section{Literature Survey}

Shahrzad Dehghani describes cluster based routing algorithms to enhance the lifetime of wireless sensor networks which consume less memory. Cluster based routing in which nodes combined and these nodes combination as cluster head send messages to base station which reduce network overload. In WSNs for enhance lifetime of networks main issue is proper usage of resources. In this paper describes clustering algorithms LEACH, LEACH-C, TEEN, EEHC, DDAR, HEED and HTCE etc. These algorithms compare on the basis of scalability, energy efficiency and transmission delays [3].

Sami Alwakeel provides energy saving Adaptive algorithm for mobile wireless networks. This algorithm adjusts the nodes dynamically for efficient usage of energy. During data transmission from source to sink it select that stable for energy saving in mobile wireless sensor networks. It reduces message duplication and increase lifetime of network with less energy consumption. But in static nodes not specific paths that send data directly to base station [4].

Salim EL KHEDIRIa proposes Low-energy adaptive clustering hierarchy (O-LEACH) is a popular clustering protocol. This protocol select cluster heads and performs data aggregation processes on the clusters on the basis of residual energy. This algorithm has better stability than LEACH. This algorithm works on static nodes and dynamic nodes [5].

Karthikeyan proposes power efficient gathering in sensor information systems (PEGASIS) protocol in which formed a shortest chain form on the basis of energy consumption in nodes. When Cluster head formed near the base station it consumes less memory [6].

Zibouda Aliouat describes an algorithm for multiple hops MH-PEGASIS it increases the lifetime of network and minimizes energy consumption. Routing is single hop when cluster head at large distance from base station there is consumption of large amount of energy. Multihop PEGASIS consume less memory and it provides efficiently routing between cluster heads [7].

Rajeev Kumar proposes combination of Ant bee colony optimization and Ant colony optimization (ABCACO) which increase the lifetime of networks. Wireless sensor network WSNCABC uses hierarchical clustering. It operates iteratively and decrease the distance between cluster head and base station. It gives better performance as lifetime of networks, scalability as compare to existing algorithms [8].

Varsha Gupta and Shashi Kumar Sharma describe a modified Ant Colony optimization for head selection of cluster based on LEACH protocol. In LEACH-MA method clustering head selection on the basis of distance and energy [9].

R.U.Anitha proposes enhanced algorithm ECBR-MWSN that is Enhanced Cluster Based Routing Protocol for Mobile Nodes in Wireless Sensor Network. ECBR-MWSN select cluster head using maximum residual energy and minimum distance of cluster heads from base station [10].

\section{Clustering Routing Protocols}

Routing algorithms are finding path between nodes from source to destination. Routing algorithm with clustering used for less energy consumption and optimal use of resources. It provides reliable path for data transmission from source node to base station. In clustering network divided into several parts and each part is grouped as cluster. Clusters are group of nodes and one of node is selected as cluster head on the basis of parameters. Cluster head perform data aggregation or data fusion on received signals before forwarding to base station. Clustering reduces load for increase the network lifetime. It 
provides several advantages during routing as scalability, reduces load, energy consumption.

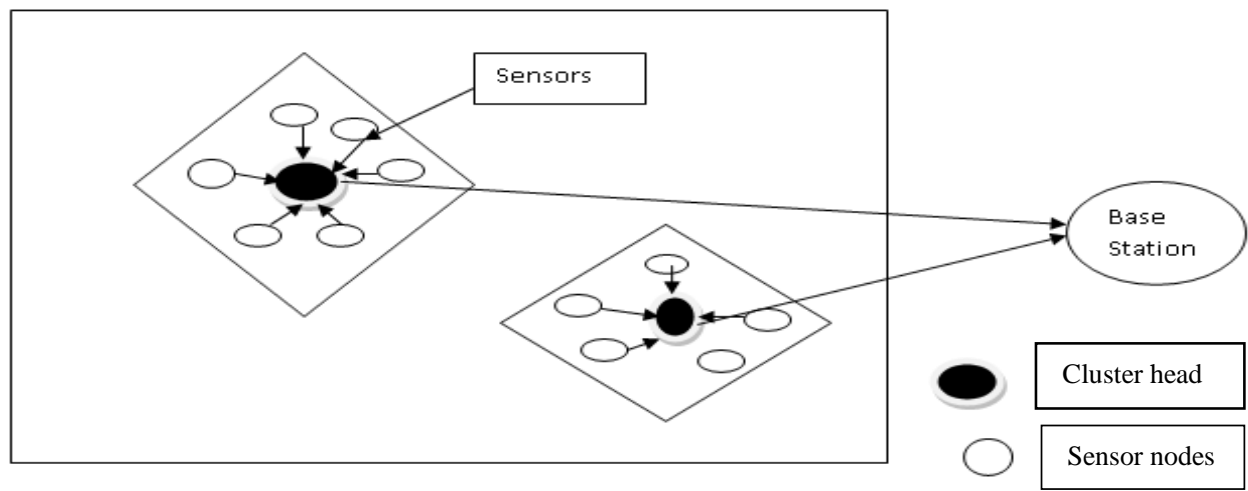

Figure 1. Architecture of Clustering in WSN

There are various clustering schemes on basis of routing. Routing techniques mainly network structure based, Path establishment based and protocols operation based. Network structure based routing protocol consist of Flat routing, Hierarchical routing, Location based routing. In this discuss hierarchical routing in briefly.

\section{Hierarchical Routing}

Hierarchical routing improves energy-efficient routing and scalability in WSNs. Hierarchical routing on the basis of clusters in network. Higher energy nodes are selected for processing of data as cluster head and low energy nodes senses data to cluster heads. It improves the lifetime, scalability of network. It reduces the traffic on network [12].

Hierarchical Routing Classified into Four Parts as: Chain based routing, tree based routing, cluster based routing and grid based routing as shown in Figure 2.

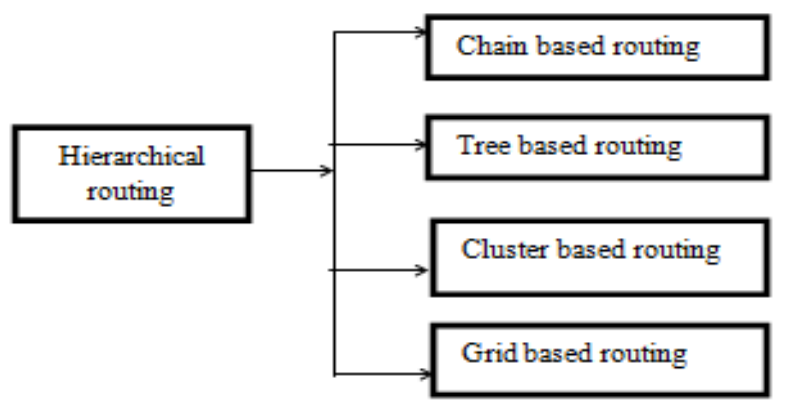

Figure 2. Types of Hierarchical Structure

4.1. Chain based Routing: In this routing one or more chains formed to connect the sensor nodes. From chain one sensor is constructed as head to perform data transmission. In Figure 3 sink selected as head node. Data delivered along chain and head node automatically. [11] 


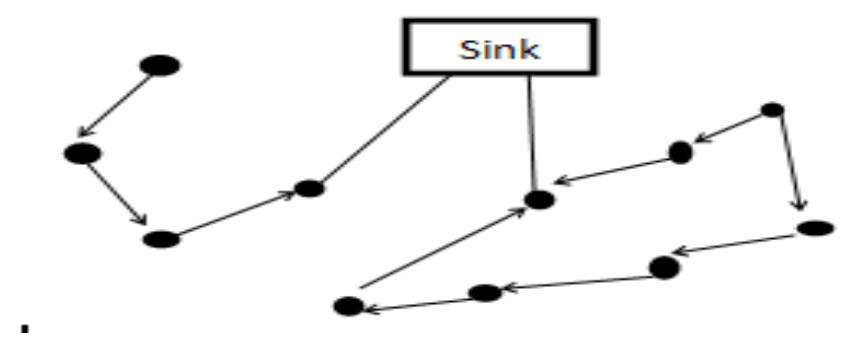

Figure 3. Chain based Routing

Main drawback of chain based topology that due to one or more chains increases number of hops and delay occurred. Sector chain based routing protocol proposed [12] in which target network is divided in to sectors. It balances number of nodes and arrange in multiple chains. Each chain has assigned a cluster head which reduces energy consumption. It also balances time length of each round for data transmission. Chain based routing protocols are

\section{A. PEGASIS \\ B. CCS}

\section{A. PEGASIS (Power Efficient Gathering in Sensor Information Systems)}

It is a chain based power efficient protocol. In this each node selects its closest neighbor as the next hop arrives in the chain. It communicates only with closest neighbor and turns data transmission to base station. Neighbor nodes are finds with usage of signal strength with calculating distance between nodes. In this energy and lifetime reduces per round. PEGASIS avoids cluster formation of nodes and uses only one node in a chain for transmit data to BS rather than using multiple nodes. It is not contain mobility nodes. In this if head node dead, network start select new head node for chain formation. It reduces the cluster head selection burden with usage of chain [7].

In PEGASIS necessary that all neighbor nodes are joined with each other so less energy consumption of radio signals. Some disadvantages of this protocol are that there is necessary that all nodes are connected to each other. It uses greedy algorithm for chain construction it uses long path for topology construction. PEGASIS avoids clustering overhead. It also reduces power consumption.

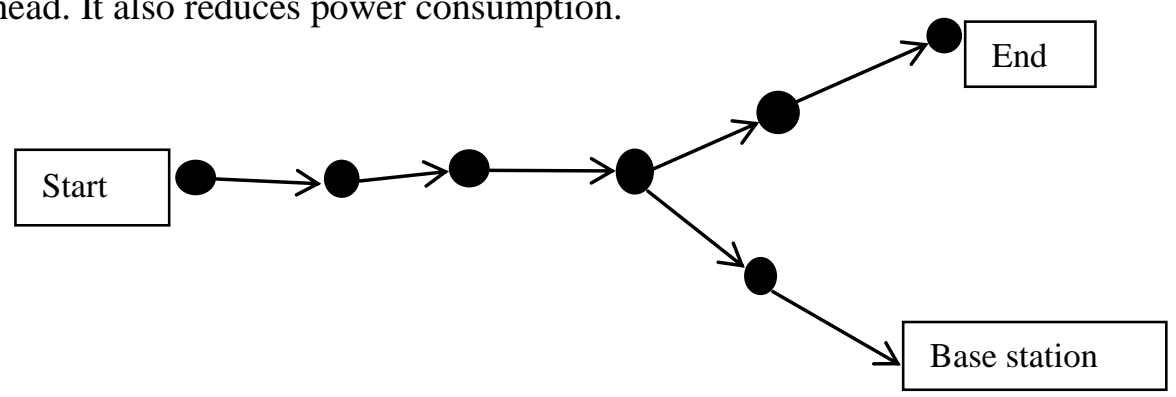

Figure 4. PEGASIS Chain based Protocol

B. CCS (Concentric Clustering Scheme): It is centralized chain based routing in which multiple chains formed. In this routing include the location of base station for less energy consumption and increases life time of network in to concentric circular part and each part has assigned a cluster head. According to distance from base station there is assigned a level [13]. The Concentric circular part which is nearest the base station allocates a level 1 and with distance increases level number also increases. In each track formed a multiple chains. At each level cluster head selected and cluster head transfer data to its two 
neighbor cluster head. Due to communication from $\mathrm{CH}$ to $\mathrm{CH}$ distances reduced and consume less energy for data transmission [14].

In CCS, energy consumption decreases because length of base station and cluster head decreases.

\subsection{Tree based Routing Protocols}

In tree-based routing, tree is constructed by all sensor nodes in a network. Data delivered from leaf nodes to their parent nodes .Parent nodes after receiving data send to its parent nodes. This process continues up to root node. It balances the energy consumption between the nodes and extends the network lifetime compared [15]. It is same as chain-based routing. But main drawback of this clustering is that it has too many levels from root to leaf nodes. So it consumes more memory for data transmission.

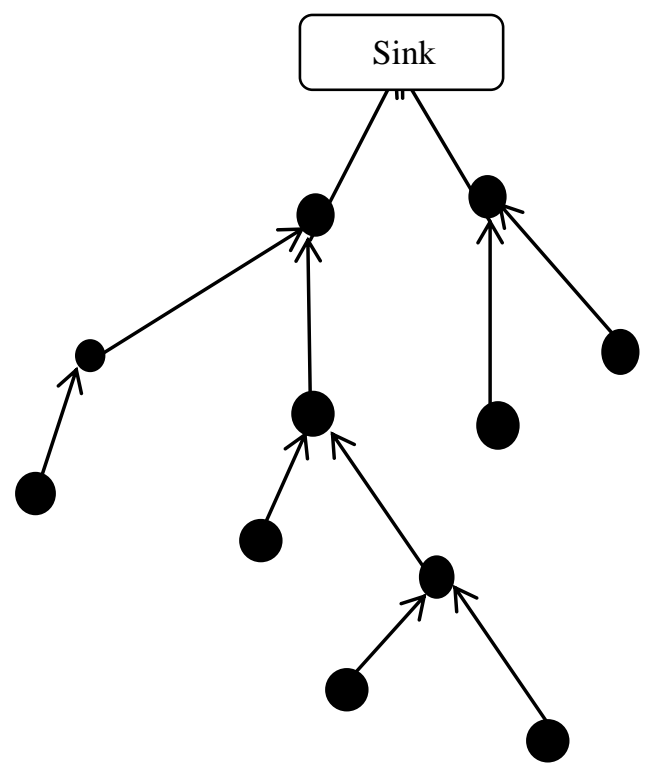

Figure 5. Tree based Routing

Various types of tree based clustering are:
A. EADAT
B. BATR
C. PEDAP
D. ETR

A. EADAT (Energy-Aware Data Aggregation Tree): The algorithm is stared from the sink node with broadcasting a control message. The sink is considered as the root node in the tree. When sensor node receives a control message for the first time, it set up timer for count down its idle state. Sensor node chooses a node which has higher residual energy and shortest path to reach a parent node. It time out of parent node it broadcast a control message to all nodes and its value increases by one hop count. If residual power less than it broadcast a help message and changes its status to sleep mode. After receiving help message from parent leaf node find a new parent node if exist. If not any parent node found it goes to danger state. In this routing distance and residual energy to factors are included. 
B. BATR (Balanced Aggregation Tree Routing): It is a tree-based routing algorithm. It finds an optimal path based on a balanced tree, in which each node consumes the equal amount of energy. In this assumed that the BS has knowledge about location of all nodes. This routing algorithm starts from base station as root node. It chooses minimum weighted edge for number of child nodes and add new nodes one by one. If neighbor node is found, the node is labeled as a leaf node. This process continues until all nodes joined in the routing tree. This routing algorithm constructs a minimum spanning tree with energy dissipation cost to achieve a minimum energy.

C. PEDAP (Power-efficient Data Gathering and Aggregation Protocol): The purpose of PEDAP is to increases network lifetime. The minimum energy cost tree is used for data transmission. This protocol uses

Prim's minimum spanning tree algorithm [16]. The sink is defined as the root of the tree. Minimum weighted edge selected for tree construction, in which one node selected from tree and second which is not in tree.

During data transmission, root node of the tree is considered as $\mathrm{CH}$. Each node receives data from its child nodes, aggregates the data with its own and delivers it to its parent node. This process continues until the aggregated data reaches the $\mathrm{CH}$. Ultimately, the data is delivered from the $\mathrm{CH}$ to the sink.

D. ETR (Enhanced Tree Routing): Tree like structure follows only parent- child relationship. In ETR each node has an updated list of neighbors' uses links to other onehop neighbors. It helps in decided that which will lead to a shortest path. These decisions can be made with minimum storage and computing cost by usage of address list [17].

\subsection{Cluster based Routing}

Cluster based routing is a hierarchical routing technique. In this cluster are formed with portioning network in to group of nodes. One node selected as cluster head on basis of residual energy. There are various types of clustering protocols as
A. LEACH
B. HEED
C. TEEN
D. APTEEN
E. LEACH-C etc.

A. LEACH (Low Energy Adaptive Cluster Hierarchy): LEACH is self-organizing clustering protocol. In this cluster head selected randomly on basis of higher energy. LEACH works in many phases as advertisement phase, cluster set up phase, steady state phase. [18] Advertisement phase in which cluster head selected randomly and nodes generate number between 0 and 1, if it is less than the threshold value, the node selected as a cluster head. In set up phase sensor nodes inform the cluster head about their membership using Carrier Sense Multiple Access(CSMA) protocol. In Steady phase sensor nodes of the network transmitting data to the Cluster head. After receiving the data, cluster head aggregates the data then forward it to the base station. Threshold value calculated as:

\section{$T n=T \backslash 1-p(\operatorname{rmod} 1 \backslash p)$ if $n \in G$ 0 otherwise}


Where p probability of each node to become $\mathrm{CH}, \mathrm{G}$ set of nodes which has not cluster head in last $1 \backslash p$ round.

B. HEED (Hybrid Energy-Efficient Distributed Routing Protocol): HEED improves lifetime of network by distributed energy consumption. HEED in which cluster head is selected on the basis of factors two factors as residual energy of sensors and communicate cost during transmission of data between sensor nodes. Cluster head selected more than once in cluster. Therefore more energy required for transmission Selection of probability on basis of

$\mathrm{CH}_{\text {prob }}=\mathrm{C}_{\text {prob }} * \mathrm{E}_{\text {residual }} \mathrm{E}_{\max }$

$\mathrm{E}_{\text {residual }}$ is current energy of nodes. $\mathrm{E}_{\max }$ is maximum energy. HEED protocol improves lifetime of network as compare to LEACH protocol [19].

C. TEEN: Threshold-sensitive Energy Efficient Protocols (TEEN) used for time specific applications. In time specific applications rapidly change possible as temperature change during a day. In this protocol form the clusters firstly and each cluster head $(\mathrm{CH})$ transmit two threshold values to group nodes. The core idea of TEEN protocol is that the cluster head is selected periodically, probability and randomly. [20]

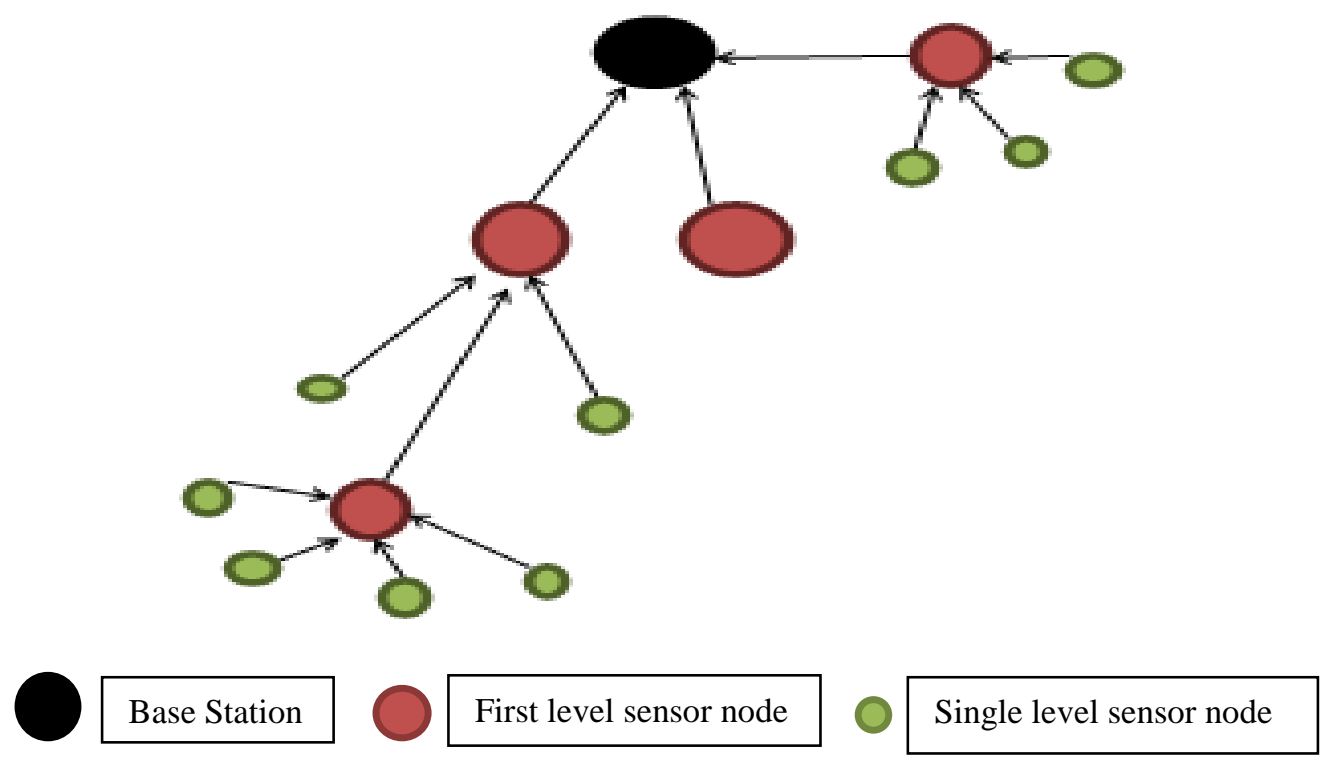

Figure 6. TEEN Protocol

Hard threshold value monitor TEEN is divided into two parts: the clustering phase and the data transmission phase. But main drawback of this algorithm that if threshold values received the nodes never communicate and no any data transmission [21]. In cluster head selection during TEEN it is not guaranteed that member nodes similar o cluster head so there is high energy consumption. For less energy consumption TEEN uses the multipath and Multihop network [22].

D. APTEEN (Adaptive Periodic Threshold Sensitive Energy Efficient Sensor Network Protocol): It is advancement of TEEN protocol. TEEN is depending on fixed threshold values, so not suitable for periodic reports for real time applications. To provide 
periodic information APTEEN is used. It is a hybrid approach because it sends data with both critical time and periodic time with hierarchical clustering approach [23]. It provides a TDMA based structure for cluster formation. In this cluster heads broadcast threshold values, physical parameters, timing limit. APTEEN consume less memory. Main disadvantage of TEEN and APTEEN is more levels of cluster formation and overhead of threshold values.

E. LEACH-C: It is based on traditional LEACH protocol and consists of rounds that are divided in set-up and steady state period. In LEACH algorithm some cluster heads can be situated near to base station or at far place. Larger the distance between cluster head and base station more will be the energy consumption. Assumptions made in LEACH-C protocol are as follows:

- Each node in network can calculate its energy level.

- Node can send information about its location to Base Station.

- Each node can send message to base station.

In LEACH distance not considered between sensor nodes. In set-up period nodes send status of energy, location and node id to base station. On basis of energy cluster head selected. Base station broadcast the node id of elected cluster head to the network. Cluster head send advertise message to all nodes. In steady-state period, according to TDMA schedule non-cluster nodes send data signals to cluster head. After data aggregation, combined messages are transmitted to base station with different spreading factor to base station [24]. LEACH-C works better under fewer loads, but for higher load complexity of selecting cluster head by centralized method degrades its performance.

4.4. Grid based Routing: In a grid-based routing network is divided into various grids with geographic approach. Grid based clustering protocol uses dynamic range based cluster head and traffic splitting which is greedy algorithm to minimize intra cluster communication cost. It also optimize inter cluster packet forwarding cost among cluster heads [25] in this routing performed without routing table.

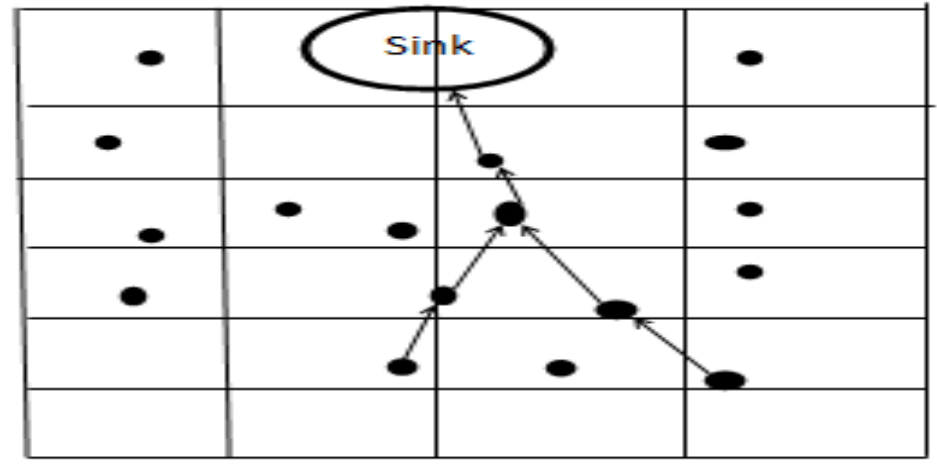

Figure 7. Grid based Routing

Various routing protocols are as:
A. PANEL
B. TTDD
C. HGMR
D. GMCAR 
A. PANEL (Position-Based Aggregator Node Election Protocol): It uses the geographical position information of the nodes. PANEL assumed sensor nodes constructed in a limited area and this area divided in to geographic clusters. It used in inter cluster communications. Reference point is computed according to position of clusters. The node that is the nearest to the reference point is considered as $\mathrm{CH}$.It satisfies with both synchronous and asynchronous applications. PANEL ensures load balances and each node has given same chance to become aggregator [26].

B. TTDD (Two-Tier Data Dissemination): In this routing approach that provides scalable and efficient data delivery to multiple mobile sinks. Grid based structure allows to mobile sinks continuously receive data in local area. [27] In this approach each source node with sink node made a rectangular grid around itself and it becomes a crossing point of this grid. For grid construction location aware sensor nodes are required. When sink node require data, it send query message by local flooding within a grid cell and these queries are send to the source node. Data is then forwarded to the sink using same path.

C. HGMR (|Hierarchical Geographic Multicast Routing): It is a grid-based hierarchical protocol. It combines both HRPM (Hierarchical Rendezvous Point Multicast) and GMR (Geographic Multicast Routing) protocols. GMR improves the forwarding efficiency while HRPM is reduces the encoding overhead. In HRPM, the network is hierarchically partitioned into multiple cells using the mobile geographic hashing idea. It provides energy efficiency and scalability to large networks [28].

D. GMCAR (Grid-based Multipath with Congestion Avoidance Routing): Sensor network divided into grids. In each grid, one sensor nodes is selected as a head node which is responsible for delivery of data received from any node in a grid. Data received from other head node also transfer to neighbor grids. Multiple paths formed from head node to sink node stored in routing table. [29] In this paper cluster head advertise with dynamic range and splitting of traffic for minimize intra cluster communications cost. It also optimize inter cluster packet forwarding cost for energy consumption between cluster heads.

\section{Advantages of clustering:}

1. Clustering reduce overhead for data transmission between network topology.

2. Consume less memory during routing between sensor nodes.

3. It provides bandwidth reusability and reduces collisions of channels.

4. Network stability increases due to less usage of energy by clusters.

5. Only Cluster heads of several nodes and gateway nodes maintain routing in network.

6. Increase lifetime of networks. 
Analysis of Hierarchical Routing Techniques

Table 1. Cluster based Routing Techniques

\begin{tabular}{|l|l|l|l|l|l|}
\hline $\begin{array}{l}\text { Various } \\
\text { Parameters }\end{array}$ & LEACH & HEED & TEEN & APTEEN & LEACH-C \\
\hline Power Usage & High & Low & High & Moderate & High \\
\hline Scalability & Good & Good & Good & Good & Good \\
\hline $\begin{array}{l}\text { No. of cluster } \\
\text { groups }\end{array}$ & Multiple & Multiple & Multiple & Multiple & Multiple \\
\hline $\begin{array}{l}\text { Selection of } \\
\text { Cluster head }\end{array}$ & $\begin{array}{l}\text { Based on } \\
\text { probabili } \\
\text { stic } \\
\text { approach }\end{array}$ & $\begin{array}{l}\text { Based on } \\
\text { residual energy }\end{array}$ & $\begin{array}{l}\text { Based on } \\
\text { attribute }\end{array}$ & $\begin{array}{l}\text { Based on } \\
\text { attributes and } \\
\text { time limit }\end{array}$ & $\begin{array}{l}\text { Based on } \\
\text { energy level } \\
\text { and distance } \\
\text { from BS }\end{array}$ \\
\hline Traffic & High & High & Low & Low & Medium \\
\hline QoS & Low & Low & Moderate & Moderate & Low \\
\hline $\begin{array}{l}\text { Energy } \\
\text { efficiency }\end{array}$ & Poor & Poor & High & High & Medium \\
\hline $\begin{array}{l}\text { Algorithm } \\
\text { Complexity }\end{array}$ & Low & Low & High & High & Moderate \\
\hline
\end{tabular}

Table 2. Chain based Routing Techniques

\begin{tabular}{|l|l|l|}
\hline Various Parameters & PEGASIS & CCS \\
\hline Power Usage & High & Low \\
\hline Scalability & Good & Low \\
\hline No. of cluster groups & Single & Multiple \\
\hline $\begin{array}{l}\text { Selection of Cluster } \\
\text { head }\end{array}$ & $\begin{array}{l}\text { Based on } \\
\text { distance } \\
\text { from BS }\end{array}$ & $\begin{array}{l}\text { Based on } \\
\text { Distance } \\
\text { from BS }\end{array}$ \\
\hline Traffic & Low & High \\
\hline QoS & Low & Low \\
\hline Energy efficiency & High & Very low \\
\hline Algorithm Complexity & High & Moderate \\
\hline
\end{tabular}

Table 3. Tree based Routing Techniques

\begin{tabular}{|l|l|l|l|l|}
\hline $\begin{array}{l}\text { Various } \\
\text { Parameters }\end{array}$ & EADAT & BATR & PEDAP & ETR \\
\hline Power Usage & Moderate & High & Moderate & Moderate \\
\hline Scalability & Low & Low & Low & Moderate \\
\hline $\begin{array}{l}\text { No. of cluster } \\
\text { groups }\end{array}$ & Single & Multiple & Multiple & Single \\
\hline $\begin{array}{l}\text { Selection of } \\
\text { Cluster head }\end{array}$ & $\begin{array}{l}\text { Depends on } \\
\text { root of node }\end{array}$ & $\begin{array}{l}\text { Depends on root } \\
\text { of node }\end{array}$ & $\begin{array}{l}\text { Depends on root } \\
\text { of node }\end{array}$ & $\begin{array}{l}\text { Depends on root } \\
\text { of node }\end{array}$ \\
\hline Traffic & High & High & Moderate & Moderate \\
\hline QoS & Low & Moderate & Low & Moderate \\
\hline Energy efficiency & Moderate & Low & Moderate & Moderate \\
\hline $\begin{array}{l}\text { Algorithm } \\
\text { Complexity }\end{array}$ & Low & Moderate & Moderate & Low \\
\hline
\end{tabular}




\section{Conclusion}

Wireless Sensor networks are important in computer networking. Its demand increases day by day due to usage in real time applications. Due to increases usage need a data sensed rapidly as soon as possible. Hierarchical routing technique where nodes are grouped into clusters and the interactions between the cluster members are controlled by cluster-head. In this paper describe hierarchical routing techniques and compare on basis of parameters such as scalability, energy efficiency, traffic, QoS etc.

\section{References}

[1] J. Yick, B. Mukherjee and D. Ghosal "Wireless sensor network survey", Journal of Yick et al. / Computer Networks, Elsevier 2008, vol. 52, (2008), pp. 2292-2330.

[2] S. Rani and S. H. Ahmed, "Multi-hop Network Structure Routing Protocols", Elsevier, (2016).

[3] H. Hao, K. Wang, H. Ji, X. Li and H. Zhang "Utility-based Scheduling Algorithm for Wireless Multimedia Sensor Networks", 26th Annual International Symposium on Personal, Indoor and Mobile Radio Communications - (PIMRC): MAC and Cross-Layer Design IEEE, (2015).

[4] S. Alwakeel, A. Prasetijo and N. Alnabhan, "An Adaptive Energy-Saving Routing Algorithm for Mobile Wireless Sensor Networks", 1st International Conference on Electrical and Information Technologies ICEIT'IEEE, (2015).

[5] S. El Khediri, N. Nasri, A. Wei and A. Kachouri, "A New Approach for Clustering in Wireless Sensors Networks Based on LEACH", International Workshop on Wireless Networks and Energy Saving Techniques (WNTEST) Elsevier, (2014).

[6] A. Karthikeyan, V. Jagadeep and A. Rakesh, "Energy Efficient Multihop Selection with PEGASIS Routing Protocol for Wireless Sensor Networks", International Conference on Computational Intelligence and Computing Research IEEE, (2014).

[7] Z. Aliouat and M. Aliouat "Efficient Management of Energy Budget for PEGASIS Routing Protocol", 6th International Conference on Sciences of Electronics, Technologies of Information and Telecommunications (SETIT) IEEE, (2012).

[8] R. Kumar and D. Kumar, "Hybrid Swarm Intelligence Energy Efficient Clustered Routing Algorithm for Wireless Sensor Networks", Hindawi Publishing Corporation, Journal of Sensors, vol. (2016).

[9] V. Gupta and S. Kumar Sharma, "Cluster Head Selection Using Modified ACO", Fourth International Conference on Soft Computing for Problem Solving Springer, (2015).

[10] R. U. Anitha "Enhanced Cluster Based Routing Protocol for Mobile Nodes in Wireless Sensor Network", International Conference on Pattern Recognition, Informatics and Mobile Engineering (PRIME) IEEE, (2013).

[11] X. Liu, "Atypical Hierarchical Routing Protocols for Wireless Sensor Networks: A Review", Sensors Journal, vol. 15, no. IEEE 10, (2015) October.

[12] N. Duy Tan and N. Dinh Viet, "SCBC: Sector-Chain Based Clustering Routing Protocol for Energy Efficiency in Heterogeneous Wireless Sensor Network", IEEE, (2015).

[13] S. Daniel and S. Babu, "A Review of Atypical Hierarchical Routing Protocols for Wireless Sensor Networks", IOSR Journal of Electronics and Communication Engineering (IOSR-JECE), (2015) November-December.

[14] N. Gautam, W.-I. Lee and J.-Y. Pyun, "Track-sector clustering for energy efficient routing in wireless sensor networks", in Proceedings 9th Int. Conf. Comput. Inf. Technol., Xiamen, China, IEEE, (2009) October.

[15] K. Tae Kim, C. Hoon Lyu, S. Soo Moon and H. Yong Youn, "Tree-Based Clustering (TBC) for Energy Efficient Wireless Sensor Networks", 24th International Conference on Advanced Information Networking and Applications Workshops IEEE, (2010).

[16] H. "Ibrahim Korpeo, "Power Efficient Data Gathering and Aggregation in Wireless Sensor Networks", IEEE, (2003).

[17] W. Qiu, E. Skafidas and P. Hao, "Enhanced tree routing for wireless sensor networks", Elsevier, (2008).

[18] L. Yadav and C. Sunitha, "Low Energy Adaptive Clustering Hierarchy in Wireless Sensor Network (LEACH)", International Journal of Computer Science and Information Technologies, (2014).

[19] V. M. Galshetwar and A. Jeyakumar, "Energy Efficient and Reliable Clustering Algorithms HEED and ADCP of Wireless Sensor Networks: A Comparative Study", International Conference on Communication and Signal Processing, IEEE, (2014) April 3-5.

[20] W. Junwei and F. Xiaoyi, "Improved TEEN Based Trust Routing Algorithm in WSNs", 27th Chinese Control and Decision Conference (CCDC), IEEE, (2015).

[21] Z. Aliouat and S. Harous, "An Efficient Clustering Protocol Increasing Wireless Sensor Networks Life Time", International Conference on Innovations in Information Technology (IIT) IEEE, (2012). 
[22] N. Kumari, D. K. Gupta and M. Kumar Sah, "Adaptive Periodic Threshold Sensitive Energy Efficient Sensor Network Protocol", International Journal of Computer Applications (0975 - 8887), vol. 129, no. 7, (2015) November.

[23] S. Bhagyashree, S. Prashanthi and Dr. K. M. Anandkumar, "Enhancing Network Lifetime in Precision Agriculture using Apteen Protocol", International Conference on Technological Innovations in ICT for Agriculture and Rural Development IEEE, (2015).

[24] I. Sharma, R. Singh and M. Khurana "Comparative Study of LEACH, LEACH-C and PEGASIS Routing Protocols for Wireless Sensor Network", International Conference on Advances in Computer Engineering and Applications (ICACEA), (2015).

[25] M. Tamene and K. Nageswara Rao, "Grid based Clustering Protocol with Dynamic Range Cluster head Advertisement and Traffic Splitting in Wireless Sensor Networks", International Advance Computing Conference (IACC) IEEE, (2014).

[26] L. Buttyan and P. Schaffer, "PANEL: Position-based Aggregator Node Election in Wireless Sensor Networks", IEEE, (2007).

[27] H. Luo, F. Ye, J. Cheng, S. Lu and L. Zhang, "TTDD: Two-Tier Data Dissemination in Large-Scale Wireless Sensor Networks", Springer, (2005).

[28] D. Koutsonikolas, S. Das, Y. Charlie Hu and I. Stojmenovic, "Hierarchical Geographic Multicast Routing for Wireless Sensor Networks", IEEE, (2007).

[29] O. Banimelhem and S. Khasawneh, "GMCAR: Grid-based multipath with congestion avoidance routing protocol in wireless sensor networks", Elsevier, (2012). 